\title{
Membangun Ketahanan Berbasis Komunitas dalam Mengurangi Risiko Bencana di Desa Pilomonu Kabupaten Gorontalo
}

\author{
Syahrizal Koem ${ }^{1}$ \\ 1 Universitas Negeri Gorontalo
}

\begin{abstract}
Article History ABSTRACT
Received 14.04.2019

BUILDING RESILIENCE BASED COMMUNITIES IN DISASTER RISK

Received in revised form REDUCTION IN THE PILOMONU VILLAGE GORONTALO REGENCY. This 11.06.2019

Accepted 26.07.2019

Available online 20.08.2019 article discusses the concept of community-based disaster risk reduction so that it can realize community resilience to disasters. The implementation of communitybased disaster resilience programs uses participatory approaches, observation, interviews, socialization, training, and Forum Group Discussion (FGD). The establishment of the PRB and TSBM forums received a positive response from the community because Pilomonu Village was classified as a disaster-prone village, especially landslides and floods. Analysis of the resilience index conducted by the forum based on indicators and achievements found that Pilomonu Village is included in the category of 'village not yet strong' and the level of preparedness is low. Indicators of community disaster resilience that have been established and adjusted in the document can be the main focus of all parties related to disaster risk management. The PRB and TSBM forum are those who have overall access to improving disaster resilience because forum skills in involving stakeholders are a determinant of the success of disaster resilience to lower-level communities. Integration between the Pilomonu Village government program and disaster risk reduction forums can guarantee the sustainability of forum performance.
\end{abstract}

KEYWORDS: Capacity, Community Resilience, Disaster Risk Reduction, Hazards, Vulnerability.

\section{PENDAHULUAN}

Bencana alam yang terjadi di wilayah yang dilaluinya menimbulkan potensi dampak yang tinggi terhadap kerusakan infrastruktur, korban jiwa, dan kerugian ekonomi. Tingginya dampak bencana menjadi perhatian serius dalam skala global. Keseriusan tersebut beralasan karena risiko bencana terus meningkat. Kejadian bencana disuatu

${ }^{1}$ Corresponding author: Jurusan Ilmu dan Teknologi Kebumian, Fakultas Matematika dan IPA, Universitas Negeri Gorontalo, Jl. Jendral Sudirman, Kota Gorontalo 96128, Indonesia; Email: s.koem@ung.ac.id 
wilayah dapat berdampak di wilayah lain serta diperparah dengan meningkatnya kerentanan dan dalam dua dekade terakhir lebih dari 200 juta orang terkena bencana setiap tahun (ISDR, 2005). Indonesia merupakan wilayah yang memiliki potensi terjadinya bencana sehingga menarik untuk dikaji karena terletak di wilayah ring of fire. Menurut Paton (2009) negara-negara yang terletak di wilayah ring of fire menghadapi peningkatan risiko bencana seperti gempa bumi, tsunami, badai, topan, banjir dan kebakaran hutan. Selain itu, jumlah kejadian bencana geologi dan hidrometeorologi menunjukkan trend peningkatan serta memberikan dampak pada sektor ekonomi, lingkungan, dan kehidupan (Adi, 2013; Amri et al., 2016).

Realitas peningkatan jumlah kejadian bencana yang telah terjadi dan yang akan dihadapi oleh masyarakat tidak dapat dipungkiri. Oleh karena itu, membutuhkan program-program penanggulangan guna mengurangi risiko yang lebih besar, sehingga terwujud masyarakat yang memiliki ketahanan terhadap bencana. Membangun ketahanan bencana dilevel desa terkait erat dengan budaya dan jenis bahaya bencana dalam suatu kemunitas yang ada di desa, karena indikator bencana berbeda pada setiap komunitas masyarakat (Ostadtaghizadeh et al., 2015). Selain itu, hasil identifikasi tekait ketahanan bencana masyarakat masih kurang (Jenkins, 2015). Sebagai contoh, studi yang dilakukan oleh Lassa et al., (2018) di Desa Toineke Nusa Tenggara Timur, menginformasikan bahwa dokumen penilaian risiko bencana tidak sepenuhnya diadopsi oleh masyarakat. Oleh karena itu, komunitas masyarakat bawah (grass root) menjadi pilar utama dalam upaya mengurangi risiko bencana. Komunitas masyarakat tersebut perlu pendampingan dalam peningkatan kapasitas penanggulangan, terutama dalam melakukan penyusunan dokumen analisis kapasitas, kerentanan, dan risiko bencana. Program pendampingan perlu dilakukan agar komunitas mampu menghasilkan analisis mengenai risiko bencana di Desa Pilomonu.

Sejak program ini dilaksanakan, belum ada komunitas masyarakat yang dibentuk khusus melaksanakan program peyusunan rencana pengurangan risiko bencana di Desa Pilomonu. Di sisi lain, desa ini memiliki potensi terjadinya bencana yang cukup tinggi, berdasarkan informasi yang diperoleh dari wawancara dengan masyarakat bahwa bencana banjir pernah terjadi mencapai ketinggian \pm 1 meter. Dampak dari kejadian banjir tersebut menyebabkan lahan pertanian rusak berat, namum tidak terdapat jumlah korban jiwa. Selain itu, dampak yang dirasakan oleh masyarakat berupa krisis air bersih serta aktifitas masyarakat terganggu diakibatkan meluapnya air sungai. Berdasarkan sejarah kejadian bencana hidrometeorologi lainnya seperti kekeringan, Kecamatan Mootilango termasuk di dalamnya Desa Pilomonu mengalami 7 kali kejadian kekeringan skala tahunan sejak tahun 1982-2016 (Koem \& Rusiyah, 2017). Oleh karena itu, terbentuknya komunitas masyarakat sebagai unsur yang berperan dalam mengurangi risiko bencana di Desa Pilomonu menjadi salah satu prioritas utama.

Konsep pengurangan risiko bencana berbasis komunitas menjadi salah satu program prioritas nasional, konsep ini pula telah menarik perhatian bagi komunitas akademik dan profesional untuk menghasilkan kerangka kerja yang terkemuka (Lassa et al., 2018). Peran komunitas dalam pengurangan risiko bencana dipandang mampu menjadi pendorong, menjaga risiko sosial, sebagai sumber ide dan pengetahuan serta dapat bekerjasama dengan pemerintah, organisasi international, NGO, dan swasta dalam upaya mengurangi risiko bencana (Van Niekerk et al., 2018). Atikel ini bertujuan membahas konsep pengurangan risiko bencana berbasis masyarakat sehingga dapat mewujudkan ketahanan 
masyarakat terhadap bencana. Lingkup kerja dalam implementasi program ini yaitu pembentukan forum Pengurangan Risiko Bencana (PRB) dan Tim Siaga Bancana Masyarakat (TSBM). Forum PRB dan TSBM dibekali dengan materi sosialisasi dan pelatihan agar anggota forum mengetahui bagaimana kerangka kerja dalam mengurangi risiko bencana.

\section{METODE PELAKSANAAN}

Ketinggian rata-rata wilayah Desa Pilomonu berada pada kisaran 25-800 meter, dengan topografi perbukitan di bagian utara (Gambar 1). Desa Pilomonu memiliki tanah yang cukup subur dengan tekstur halus dan kemerahan. Penggunaan lahan (landuse) di Desa Pilomonu meliputi: ladang, permukiman, tanah lapang, tanah kas desa dan lainnya. Desa Pilomonu memiliki 6 Dusun yang terdiri dari: Dusun Biluhu, Dusun Tehila, Dusun Irigasi Selatan, Dusun Irigasi Utara, dan Dusun Bualo. Pelaksanaan program ketahanan bencana berbasis komunitas menggunakan pendekatan partisipatif, observasi, wawancara, sosialisasi, pelatihan, dan Forum Group Discussion (FGD). Pengamatan lapangan dilakukan untuk mengetahui titik-titik rawan bencana serta jenis bencana yang sering terjadi. Luaran dari program ini menigkatnya kapasitas masyarakat mengurangi risiko bencana. Selain itu, mendorong partisipasi dan kontribusi masyarakat dalam pengambilan keputusan pembangunan di Desa Pilomonu. Langkah-langkah yang dilakukan dalam mewujudkan tujuan tersebut diuraikan sebagai berikut:

Langkah 1: membentuk komunitas masyarakat, hal ini bertujuan agar tercipta ruang diskusi dan eksekusi program ketahanan bencana berbasis komunitas, sehingga menghasilkan kebijakan pembagunan di Desa Pilomonu. Perekrutan anggota komunitas masyarakat meliputi aparat desa, karang taruna, dan warga masyarakat disetiap dusun.

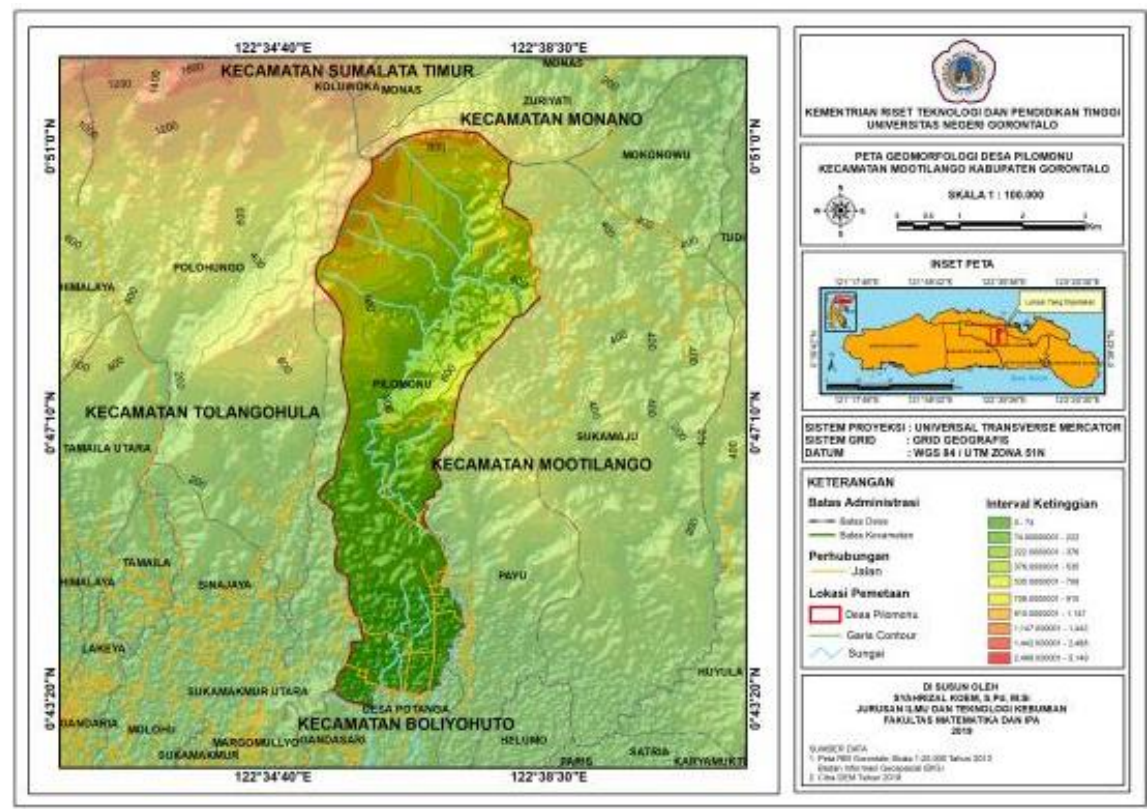

Gambar 1. Peta Desa Pilomonu dalam Konteks Geografis

Metode perekrutan anggota dilakukan dengan wawancara seputar pemahaman tentang dampak dan risko bencana serta tindakan adaptasi dan mitigasi bencana yang pernah dilakukan baik secara individu maupun kelompok. 
Langkah 2: melakukan peningkatan ketahanan komunitas masyarakat melalui sosialisasi dan pelatihan, sehingga memudahkan forum dalam menyusun kerangka kerja atau rencana pengurangan risiko bencana.

Langkah 3: melakukan analisis tentang kerentanan, kapasitas dan kajian risiko bencana di Desa Pilomonu, selanjutnya masyarakat dilatih memetakan wilayah risiko bencana serta skala risiko berdasarkan jenis bencana yang pernah terjadi di Desa Pilomonu.

Langkah 4: melakukan analisis konteks dan mobilisasi sumber daya para pemangku kepentingan (stake holder) yang mengambil peran dalam penyusunan rencana kontijensi.

Langkah 5: pengembangan rencana penanggulangan bencana, rencana aksi dan rencana komunitas. Langkah ini dilakukakan oleh anggota forum yang telah dibentuk melalui FGD.

Langkah 6: memperkuat kerjasama forum komunitas masyarakat melalui pembuatan rambu-rambu peringatan dini bencana, kemah bakti, dan penanaman pohon yang bertujuan meningkatnya rasa memiliki dan kepemimpinan masyarakat dalam pengurangan risiko bencana.

\section{HASIL DAN PEMBAHASAN}

Mewujudkan ketahanan bencana berbasis komunitas, berdampak pada peningkatan pemahaman komunitas masyarakat tentang dampak dan risiko yang ditimbulkan oleh bencana alam. Pendekatan partisipatif dalam program ini mendorang masyarakat khususnya forum komunitas melibatkan diri dalam setiap kegiatan yang memiliki relevansi dalam upaya pengurangan risiko bencana di Desa Pilomonu.

\section{Pengetahuan, Sikap, dan Persepsi Masyarakat tentang Peyebab dan Dampak Bencana}

Survei dilakukan sebagai bagian dari rencana rekrutmen anggota forum komunitas. Masyarakat yang dinilai memiliki pemahaman dan kepekaan terhadap bencana dimasukan sebagai anggota. Substansi yang ditanyakan kepada aparat desa dan masyarakat tentang pemahaman dan dampak yang ditimbulkan oleh bencana hidrometeorologi (banjir, kekeringan, dan cuaca ekstrim). Berdasarkan hasil wawancara kepada 31 responden dengan bunyi pertanyaan "Apakah anda memahami arti dari cuaca dan iklim esktrim?", di peroleh bahwa 34\% responden paham arti dari cuaca dan iklim ekstrim dan $28 \%$ lainnya sangat paham. Namun, responden yang cukup paham, kurang paham dan tidak paham masih cukup besar (Gambar 2). Selain itu masyarakat diajukan pertanyaan untuk mengetahui peyebab yang ditimbulkan oleh bencana hidrometeorologi (banjir dan kekeringan) diperoleh bahwa, penyebab utama banjir di Desa Pilomonu yaitu penebangan hutan dengan persentase sebesar $45 \%$, sedangkan peyebab utama kekeringan yaitu rusaknya hutan/cagar alam dengan persentase sebesar 47\% (Gambar 3). Persepsi masyarakat tentang penyebab bencana banjir dan kekeringan sangat beralasan disebabkan di Desa Pilomonu terdapat aktifitas penggunaan kawasan hutan, yang menurut mesyarakat aktifitas tersebut berkontribusi terhadap kejadian bencana banjir khusunya di bagian utara dan berkurangnya sumber mata air. 


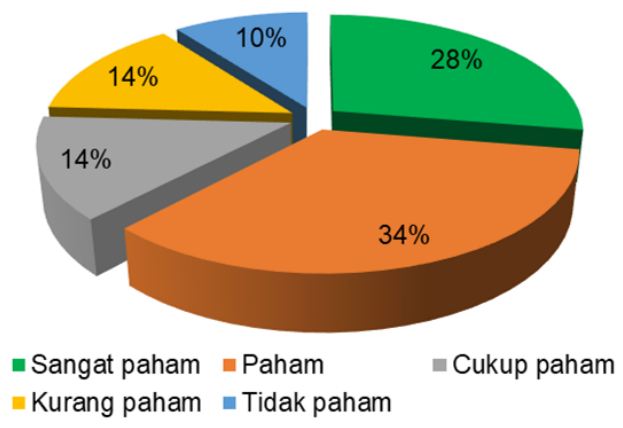

Gambar 2. Persentase Responden Memahami Cuaca dan Iklim Ekstrim

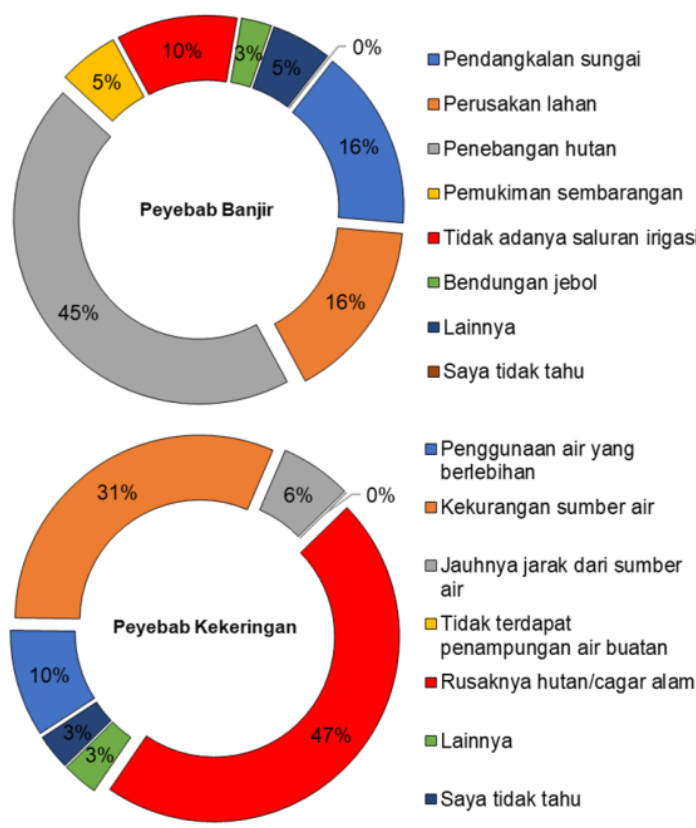

Gambar 3. Persepsi Masyarakat tentang Peyebab Banjir dan Kekeringan

Wawancara dengan masyarakat tentang sikap masyarakat terhadap bencana alam diperoleh bahwa masyarakat desa Pilomonu merasa takut dan sedih jika sewaktu-waktu bencana alam terjadi, dengan persentasi sebesar 40.6 dan 25\% (Gambar 4a). Sikap tersebut menunjukkan bahwa masyarakat belum memiliki kesiapan pada saat terjadi situasi tanggap darurat. Oleh karena itu, keinginan masyarakat untuk mengetahui dan mepelajari karakteristik bencana, adaptasi dan mitigasi bencana serta tanggap darurat bencana sangat tinggi. Keingin tersebut teridentifikasi pada saat wawancara bersama masyarakat bahwa keinginan masyarakat untuk mengetahui dan mempelajari bencana memperoleh persentasi sebesar 97\% (Gambar 4b). Kesadaran masyarakat akan potensi terjadinya bencana perlu mendapat perhatian dengan melakukan sosialisasi dan pelatihan, sehingga dapat meminimalisir rasa takut, panik, dan sedih pada masyarakat pada bencana yang akan terjadi. Selain kekhawatiran terhadap korban jiwa yang ditimbulkan oleh bencana, masyarakat juga khawatir dengan kerugian ekonomi yang ditimbulkan melalui kerusakan lahan pertanian dan menurunya produksi pertanian, 
sebab sebagian besar pekerjaan masyarakat Desa Pilomonu adalah bercocok tanam dengan mengandalkan potensi lahan dan ketersediaan air yang cukup untuk tanaman pertanian. Kerugian produksi pertanian menjadi dampak yang lebih tinggi di Desa Pilomonu dengan persentasi mencapai $32.6 \%$, selanjutnya bahaya kesehatan dengan persentasi sebesar 21.7\% (Gambar 5). Gambaran dampak bencana yang terjadi merupakan salah satu indikator dalam merumusan langkah-langkah adaptasi dan mitigasi bencana.

a

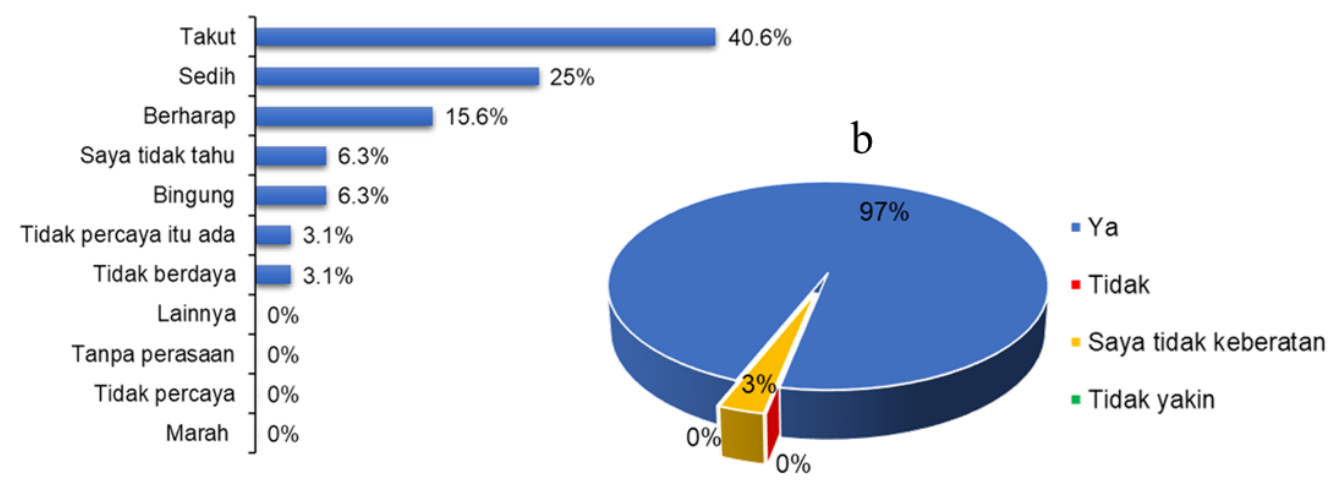

Gambar 4. (a) Sikap Responden terhadap Kejadian Bencana Alam; (b) Keinginan Responden Mempelajari Bencana Alam

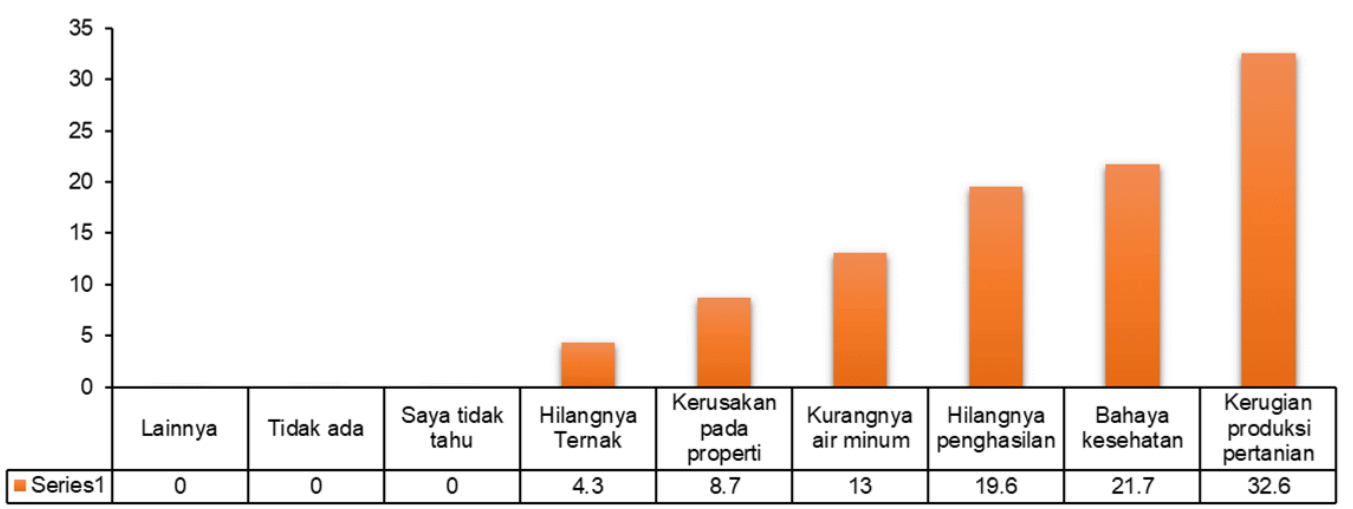

Gambar 5. Persepsi tentang Dampak Bencana Alam bagi Masyarakat

\section{Manajemen Risiko Bencana Berbasis Masyarakat}

Pengakuan international dalam upaya mengurangi risiko bencana harus dilakukan secara sistematis dan terintegrasi agar tercipta program berkelanjutan dan tata kelola yang baik (ISDR, 2005). Unsur terpenting yang perlu diadakan dalam mewujudkan upaya tersebut yaitu komunitas masyarakat yang memiliki kapasitas untuk mengelola risiko bencana, komunitas ini juga dapat menjadi bagian dalam merumuskan sistem pengelolaan risiko bencana. Komunitas tersebut merupakan unsur terdepan dalam program penanggulangan bencana. Selain itu, komunitas dianggap penting untuk meningkatkan ketangguhan warga masyarakat lainnya dalam melakukan persiapan 
sebelum, saat, dan setelah terjadi bencana. Keterlibatan individu masyarakat dalam komunitas dapat membuka peluang untuk melakukan hal-hal positif dan berkontribusi lebih banyak sehingga menciptakan lingkaran masyarakat yang berbudi luhur 'virtuous circle' (Thornley et al., 2015). Komunitas pada level masyarakat Desa Pilomonu disebut sebagai forum Pengurangan Risiko Bencana (PRB) dan Tim Siaga Bencana Masyarakat (TSBM). Kedua organ ini memiliki peran masing-masing. Pembentukan forum PRB dan TSBM di Desa Pilomonu diawali dengan musyawarah dengan berbagai pihak, diantaranya karang taruna. Forum yang dibentuk berdasarkan hasil rekrutmen yang dilakukan melalui wawancara dan diminta kesedian setiap anggota untuk terlibat secara ikhlas dan sukarela untuk bergabung.

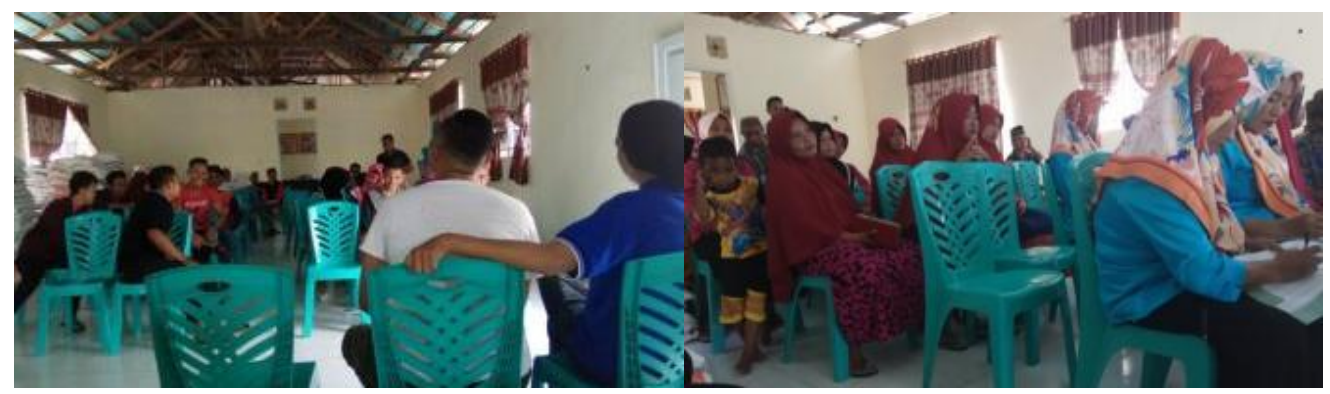

Gambar 6. Pembentukan forum PRB dan TSBM Desa Pilomonu

Terbentuknya forum PRB dan TSBM memperhatikan kesetaraan gender, artinya keterlibatan dan pemberdayaan laki-laki dan perempuan agar terjalin komunikasi yang baik serta bertujuan agar masyarakat Desa Pilomonu perlu mengetahui pentingnya kesetaraan gender dalam konteks pengurangan risiko bencana. Forum PRB dan TSBM berjumlah 57 orang berasal dari perwakilan disetiap dusun, rentang usia mereka 15-35 tahun. Pembentukan forum PRB dan TSBM mendapat respon positif dari masyarakat disebabkan Desa Pilomonu digolongkan sebagai desa rawan bencana khususnya longsor dan banjir (Gambar 6). Forum yang telah dibentuk selanjutnaya disahkan melalui SK Kepala Desa Pilomonu. Forum PRB lebih berperan pada identifikasi dan analisis risiko bencana dan langkah-langkah penanggulangan bencana, artinya forum PRB melakukan kegiatan-kegiatan prabencana yang beranggotakan 21 orang, sedangkan TSBM berperan pada kegiatan sebelum bencana, saat tanggap darurat, dan setelah bencana terjadi, sehingga TSBM memiliki anggota lebih banyak dari forum PRB yaitu berjumlah 36 orang.

\section{Sosialisasi dan Pelatihan Forum PRB dan TSBM Desa Pilomonu}

Sosialisasi dan pelatihan dilaksanakan setelah forum PRB dan TSBM terbentuk dan dikukuhk an, kegiatan ini bertujuan agar tercipta kesadaran dan pemahaman yang baik tentang risiko bencana pada tingkat masyarakat dan mampu mengidentifikasi cara untuk meningkatkan ketahanan terhadap risiko-risiko bencana (Gero et al., 2011). Fasilitator dalam kegitan sosialisasi dan pelatihan yaitu Badan Penanggulangan Bencana Daerah (BPBD) Provinsi Gorontalo, yang memberikan materi sekaligus memberikan pelatihan pada kegiatan tersebut. Substansi materi sosialisasi mengenai pijakan hukum yang mendukung pentingnya forum tersebut dibentuk dan memiliki legalitas. Selain itu, setiap anggota forum mengetahui tantangan serta konsekuensi menjadi bagian dari forum. Agar semua pemangku kepentingan mengetahui posisi strategis dari forum tersebut, untuk berkontribusi dalam pembangunan di desa yang lebih efektif dan efisien sebagaimana mandat dalam Undang-Undang dan Permen. Target utama legalitas forum tersebut yaitu terciptanya koordinasi yang baik semua pemangku kepentingan dalam upaya 
mengantisipasi risiko bencana di Desa Pilomonu. Menurut Shaw (2006) pentingnya integrasi dan koordinasi dengan pendekatan top-down dan bottom-up antara pemerintah, institusi lokal, dan masyarakat dapat meningkatkan efektifitas pengambilan kebijakan pembangunan dan implementasi program kebencanaan sampai ke masyarakat tingkat bawah (grass root).

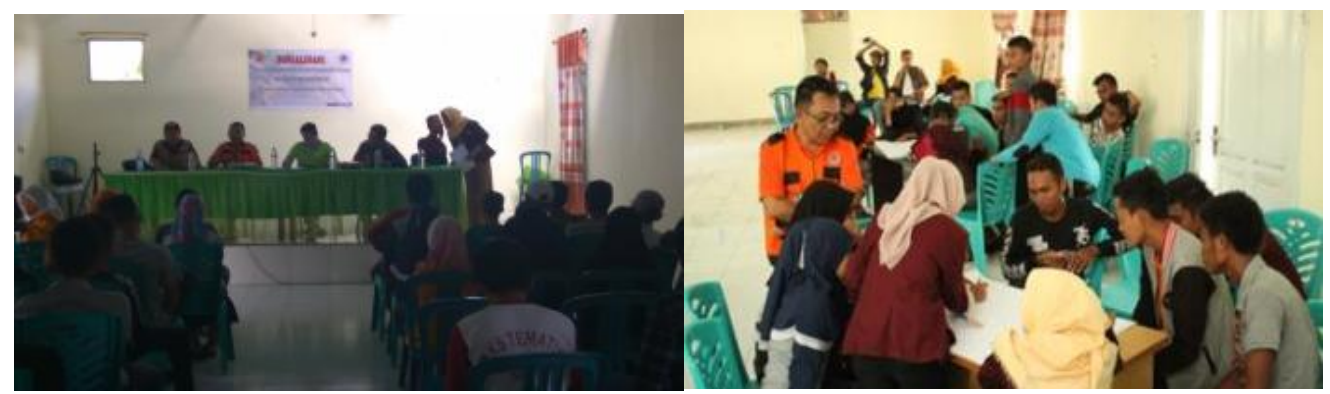

Gambar 7. Sosialisasi dan Pelatihan Forum PRB dan TSBM Desa Pilomonu

Mengenali kondisi geografis wilayah menjadi salah satu pembahasan utama dalam sosialisasi dan pelatihan, tujuannya agar forum dengan mudah mengidentifikasi tingkat risiko yang akan ditimbulkan oleh bencana (Gambar 7). Kondisi geografis yang dimaksud dia ntaranya kondisi vegetasi, perbukitan, sungai serta potensi luas dampak bencana yang dihubungkan dengan aktivitas masyarakat. Melalui metode FGD anggota forum dilatih agar dapat mengidentifikasi dan menentukan jenis bencana yang sering terjadi, menentukan wilayah yang terke na dampak bencana, selanjutnya menentukan tingkat kerentanan, kapasitas dan risiko bencana. Hasil identifikasi kemudian dipresentasikan oleh perwakilan kelompok (Gambar 8).

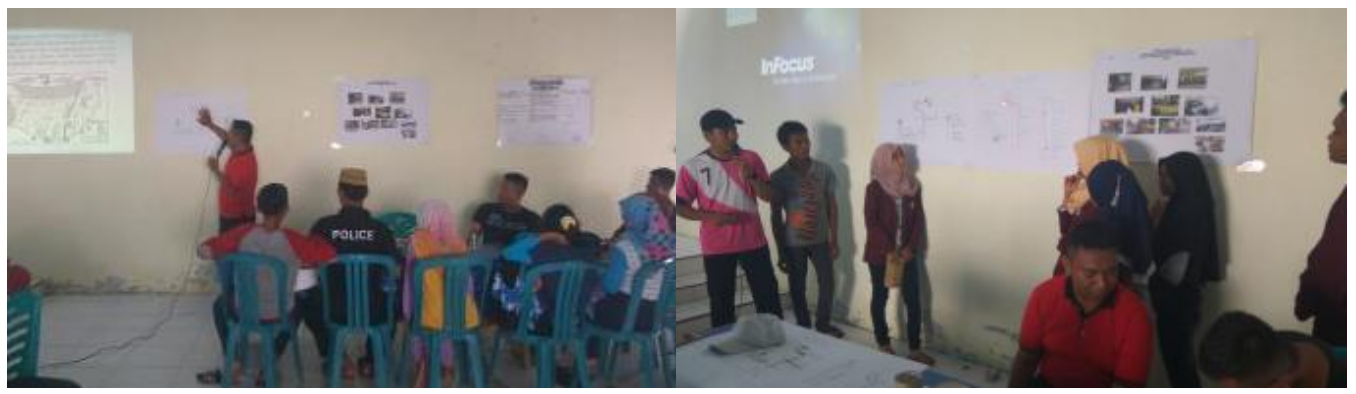

Gambar 8. Pemaparan Wilayah yang Terdampak Bencana oleh Forum

Secara umum, pelatihan ini sebagai upaya agar forum dapat menyusun dokumen desa tangguh bencana yang dapat dijadikan sebagai salah satu rujukan dalam pengambilan kebijakan pembangunan di Desa Pilomonu. Dampak langsung dari sosialisasi dan pelatihan ini, menciptakan perilaku siaga dan tangguh bencana dalam diri anggota forum sehingga mendorong forum untuk melakukan koordinasi dan kolaborasi dengan sumua pihak yang terkait dengan pengurangan risiko bencana di Desa Pilomonu. Keberhasilan dari pelatihan ini dapat berupa perencanaan yang matang dan terstruktur serta tindakan yang tepat saat situasi bencana.

\section{Rencana Kesiapsiagaan Bencana}

Tindak lanjut setelah dilaksanakanya sosialisasi dan pelatihan kepada forum PRB dan TSBM yaitu melibatkan masyarakat dalam peyusunan rencana kesiapsiagaan bencana yang meliputi rencana penanggulangan bencana, rencana aksi komunitas, rencana kontijensi, dan kajian risiko bencana. Keterlibatan penuh anggota forum sangat 
diperlukan dalam menghasilkan dokumen perencanaan kesiapsiagaan bencana sampai pada implementasi, monitoring dan evaluasi. Berdasarkan hasil identifikasi skala dampak bencana berdasarkan kejadian dan potensi bencana bahwa banjir memiliki skala dampak yang 'tinggi', sedangkan tanah longsor memilki skala dampak 'sedang'. Level skala dampak tersebut berdasarkan kejadian banjir tahun 2012 yang berskala tinggi terutama di Dusun Pasir Putih dan tanah longsor dengan skala sedang terjadi di Dusun Bualo. Dampak yang ditimbulkan oleh bencana tersebut yaitu rumah warga dan lahan pertanian rusak serta kerusakan infrastruktur. Kajian indeks penduduk terpapar yang dilakukan oleh forum diperoleh bahwa indeks penduduk terpapar akibat banjir dalam kategori tinggi dan tanah longsor kategori rendah. Hasil kajian indeks kerentanan diperoleh bahwa bencana tanah longsor dengan tingkat kerentanan yang rendah, sementara bencana kekeringan pada tingkat kerentanan sedang dan bencana banjir pada tingkat kerentanan tinggi.

Analisis indeks ketangguhan yang dilakukan oleh forum berdasarkan indikator dan capaian, diperoleh bahwa Desa Pilomonu termasuk dalam kategori 'desa belum tangguh' dan tingkat kesiapsiagaan yang rendah. Selanjutnya, analisis risiko yang dilakukan oleh forum diperoleh bahwa risiko ancaman banjir berada pada skala tinggi, sedangkan untuk risiko tanah longsor dan kekeringan pada skala rendah. Berdasarkan kajian-kajian yang telah dilakukan, selanjutnya forum menentukan tindakan penanggulangan bencana, alokasi tugas dan sumber daya serta format monitoring dan evaluasi. Selain itu, forum melakukan penyusunan rencana aksi komunitas pada setiap sektor yang relevan dengan kajian risiko bencana. Salah satu aspek yang disusun oleh forum yaitu rencana kontijensi, yang merupakan panduan bagi pemerintah desa dan masyarakat dalam melaksanakan kegiatan pengurangan risiko bencana.

Substansi rencana kontijensi yang disusun meliputi penilaian bahaya dan penentuan kejadian, pengembangan skenario, kebijakan dan strategi, perencanaan sektoral, formalisasi penanganan bencana, dan rencana tindak lanjut. Semua poin yang dibahas dalam rencana kontijensi membutuhkan keterlibatan penuh pemangku kepentingan dalam implementasinya. Sebagai contoh, keterlibatan melakukan peninjuan secara berkala rencana-rencana kesiapsiagaan berdasarkan perubahan kondisi, dengan tujuan untuk memastikan respon yang cepat dan efektif yang sesuai untuk kebutuhan lokal (ISDR, 2005). Secara keseluruhan, indikator ketahanan bencana masyarakat yang telah ditetapkan dan diruaikan dalam dokumen, dapat mejadi fokus utama seluruh pihak yang terkait dengan penanggulangan risiko bencana. Indikator ketahanan harus dapat didefinisikan dan diukur sebagaimana yang dikemukakan oleh Ostadtaghizadeh et al., (2015) meliputi sosial, ekonomi, kelembagaan, fisik, dan alam.

\section{Kerja Lapangan}

Aspek keberhasilan rencana pengurangan risiko bencana yaitu forum PRB dan TSBM lebih proaktif dalam mengimplementasikan rencana yang telah dirancang bersama. Salah satu kerja lapangan yang dilakukan forum yaitu melakukan pemasangan rambu-rambu peringatan dini bencana berdasarkan hasil kajian (Gambar 9). Tujuannya agar dapat menuntun masyarakat dalam melakukan penyelamatan diri pada situasi darurat khususnya di titik-titik rawan. Karaktersitik sistem peringatan dini yaitu mudah dipahami dalam memberikan informasi bahaya bencana dan memungkinkan masyarakat yang terkena dampak bencana untuk segera melakukan penyelamatan diri dan properti (Pineda, 2015). Sebagai contoh, ketika terjadi situasi darurat rambu-rambu jalur evakuasi 
harus bebas hambatan agar memudahkan masyarakat menuju titik $\mathrm{k}$ umpul. Penentuan titik kumpul oleh forum juga memenuhi kriteria seperti daya tampung, jarak mudah dijangkau, serta terhindar dari dampak bencana dibandingkan dengan titik lainnya.

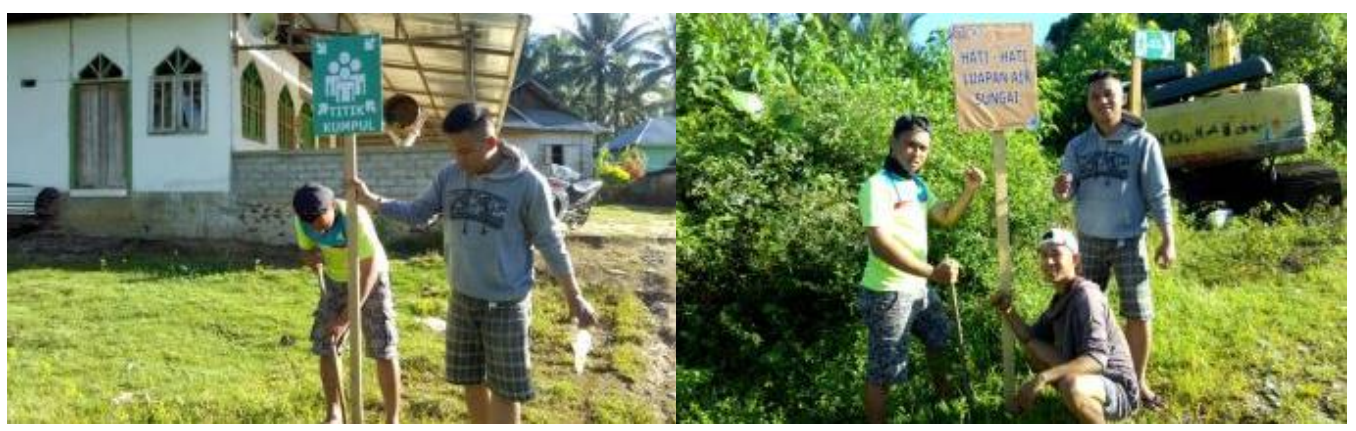

Gambar 9. Pemasangan Rambu-Rambu Peringatan Dini Bencana

Interakasi yang intens dilakukan oleh forum PRB dan TSBM akan miningkatkan rasa percaya diri. Forum lebih terbuka dalam melakukan dialog dengan pihak-pihak terkait agar tercapainya program pengurangan risiko bencana. Kegiatan kemah bakti dan penanaman pohon sebagai sarana bagi forum untuk berkomunikasi dengan pegiat pencinta alam seperti GMPA Mutiara (Generasi Muda Pencinta Alam), sehingga dapat meningkatkan kesiapsiagaan bencana.
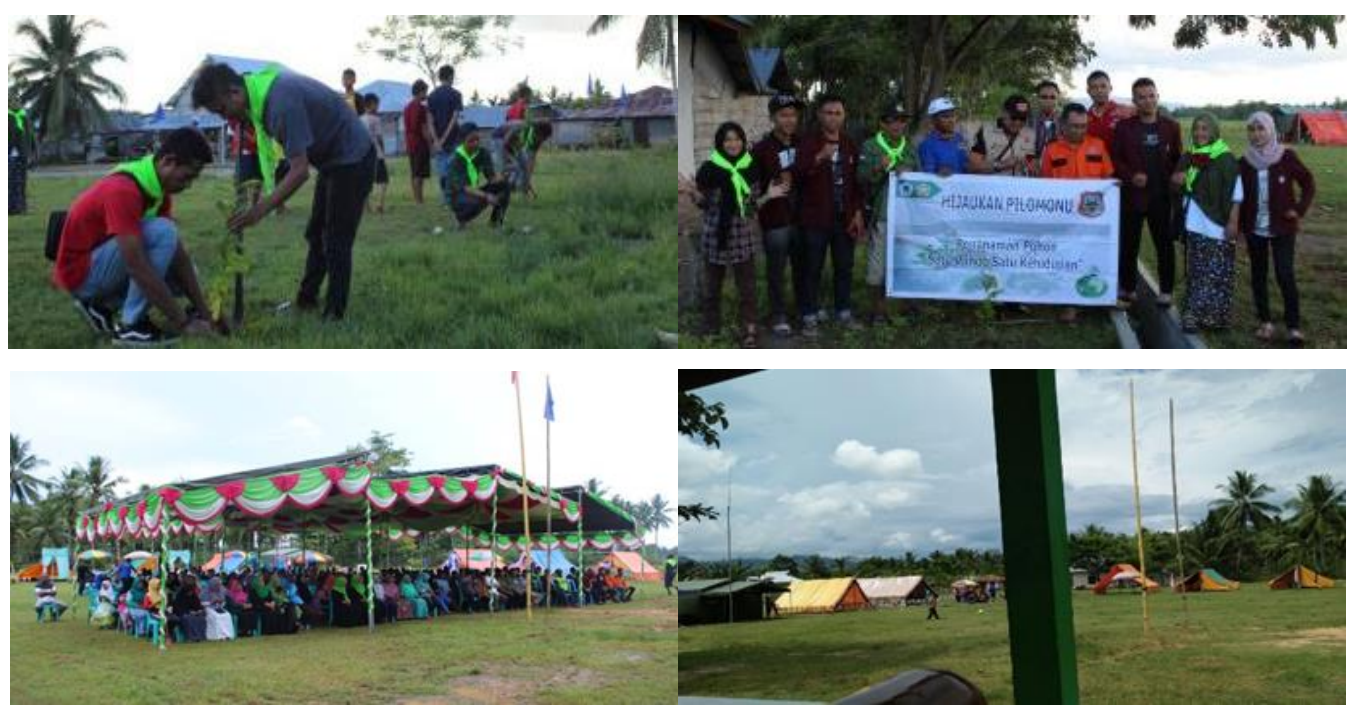

Gambar 10. Penanaman Pohon dan Kemah Bakti Forum Bersama, BPBD, GMPA Mutiara, Dan Masyarakat

Kegiatan penanaman pohon sebagai upaya melakukan konservasi yang dapat membantu mencegah kerusakan lingkungan (Eraku \& Koem, 2018). Pada kegiatan kemah bakti, forum dan masyarakat mendapat pengarahan langsung dari pemerintah dearah tentang pentingnya program kesiapsigaan bencana. Kegiatan yang dihadiri oleh pemerintah, LSM, dan masyarakat dapat memberikan pemahaman kepada forum pentingnya melibatkan pemangku kepentingan dalam mensukseskan program pengurangan risiko bencana (Gambar 10). 


\section{Tindak Lanjut}

Upaya meningkatkan kapasitas pengurangan risiko bencana, membutuhkan program mitigasi dan kesiapsiagaan bencana yang secara rutin dilaksanakan oleh Forum PRB dan TSBM. Selain itu, pemenuhan fasilitas sarana dan prasarana secara bertahap perlu dilakukan untuk menunjang terselenggaranya kegiatan yang barkaitan dengan peningkatan keterampilan penanggulangan bencana. Pemerintah daerah melalui BPBD dan pemerintah desa perlu melakukan evaluasi secara rutin terhadap program yang direncanakan oleh forum, untuk memastikan keberlanjutan program pengurangan risiko bencana di Desa Pilomonu.

\section{SIMPULAN}

Forum PRB dan TSBM merupakan unsur yang memiliki peran terdepan dalam pengurangan risiko bencana di Desa Pilomonu. Forum juga sebagai pihak yang memiliki akses secara menyeluruh dalam meningkatkan ketahanan bencana, sebab keterampilan forum dalam melibatkan pemangku kepentingan menjadi penentu suksesnya ketahanan bencana sampai ke masyarakat tingkat bawah. Penguasaan secara mendalam rencana kesiapsiagaan bencana oleh anggota forum dapat mengokohkan eksistensi forum PRB dan TSBM. Langkah selanjutnya forum melakukan sosialisasi rencana tersebut kepada pemangku kepentingan atau otoritas lokal dan masyarakat sehingga secara bersama-sama melakukan implementasi, monitoring dan evaluasi. Namun, komunitas harus cukup sumber daya agar memungkinkan melakukan peran vital ini (Thornley et al., 2015). Integrasi antara program pemerintah Desa Pilomonu dan forum pengurangan risiko bencana dapat menjamin keberlanjutan kinerja forum.

\section{UCAPAN TERIMA KASIH}

Terima kasih kami ucapkan kepada Lembaga Penelitian dan Pengabdian Pada Masyarakat (LP2M) Universitas Negeri Gorontalo atas dukungan dana pada kegiatan KKS Tematik Desa Tangguuh Bencana (DESTANA). Terima kasih kami kepada BPBD Provinsi Gorontalo sebagai fasilitator pada kegiatan ini. Ucapan terima kasih kepada kepala desa dan warga masyarakat Desa Pilomonu atas kesediaanya menjadi mitra, sehingga program ini terlaksana dengan baik.

\section{REFERENSI}

Adi, S. (2013). Karakterisasi bencana banjir bandang di Indonesia. Jurnal Sains dan Teknologi Indonesia, 15(1), 42-51.

Amri, M. R., Yulianti, G., Yunus, R., Wiguna, S., Adi, A. W., Ichwana, A. N., ... Septian, R. T. (2016). Risiko bencana Indonesia. Jakarta: Badan Nasional Penaggulangan Bencana.

Eraku, S. S., \& Koem, S. (2018). Konservasi lingkungan berbasis masyarakat di Desa Motilango, Kabupaten Gorontalo Utara. Ethos: Jurnal Penelitian Dan Pengabdian, 6(1), 107-113. 
Gero, A., Méheux, K., \& Dominey-Howes, D. (2011). Integrating community based disaster risk reduction and climate change adaptation: examples from the Pacific. Natural Hazards and Earth System Science, 11(1), 101-113. doi: 10.5194/nhess-11-1012011

ISDR [International Strategy for Disaster Reduction]. (2005). Hyogo framework for action 2005-2015: building the resilience of nations and communities to disasters. Final Report of the Word Conference on Disaster Reduction, 2006 (A/CONF. 206/6). Geneva: United Nations.

Jenkins, S. (2015). Resilience: The new paradigm in disaster management-An Australian perspective. World Journal of Engineering and Technology, 3(3), 129-139. doi: 10.4236/wjet.2015.33C020

Koem, S., \& Rusiyah. (2017). Monitoring of drought events in Gorontalo regency. IOP Conference Series: Earth and Environmental Science, 98, 012053. doi: 10.1088/1755$1315 / 98 / 1 / 012053$

Lassa, J. A., Boli, Y., Nakmofa, Y., Fanggidae, S., Ofong, A., \& Leonis, H. (2018). Twenty years of community-based disaster risk reduction experience from a dryland village in Indonesia. Jàmbá: Journal of Disaster Risk Studies, 10(1), 1-10. doi: 10.4102/jamba.v10i1.502

Ostadtaghizadeh, A., Ardalan, A., Paton, D., Jabbari, H., \& Khankeh, H. R. (2015). Community disaster resilience: a systematic review on assessment models and tools. PLoS Currents, 7, $25905026 . \quad$ doi 10.1371/currents.dis.f224ef8efbdfcf1d508dd0de4d8210ed

Paton, D. (2009). Living on the ring of fire: Perspectives on managing natural hazard risk in pacific rim countries. Journal of Pacific Rim Psychology, 3(1), 1-3. doi: 10.1375/prp.3.1.1

Pineda, M. V. G. (2015). Redefining Community Based Disaster Risk Management (CBDRM) through Enhanced Early Warning Processes. International Journal of Information and Education Technology, 5(7), 543-548. doi: 10.7763/IJIET.2015.V5.565

Shaw, R. (2006). Critical issues of community based flood mitigation: Examples from Bangladesh and Vietnam. Journal of Science \& Culture Special Issue on "Flood Disaster Risk Reduction in Asia", 72(1), 1-17.

Thornley, L., Ball, J., Signal, L., Lawson-Te Aho, K., \& Rawson, E. (2015). Building community resilience: learning from the Canterbury earthquakes. Kōtuitui: New Zealand Journal of Social Sciences Online, 10(1), 23-35. doi: 10.1080/1177083X.2014.934846

Van Niekerk, D., Nemakonde, L. D., Kruger, L., \& Genade, K. F. (2018). Community-Based Disaster Risk Management. In H. Rodríguez, W. Donner \& J.E. Trainor (eds.), Handbook of disaster research (pp. 411-429). New York: Springer. 